Reseña

\section{Jesús Astigarraga y Javier Usoz (eds.). Bajo el velo del bien público. Estudios en homenaje de Guillermo Pérez Sarrión. Zaragoza, Institución Fernando el Católico, Diputación de Zaragoza, 2020, 302 pp. ISBN: 978-8499115931.}

El volumen que aquí se reseña constituye una recopilación de los trabajos presentados en el marco de unas jornadas en homenaje a Guillermo Pérez Sarrión, celebradas en mayo de 2018. El profesor Pérez Sarrión, catedrático de Historia Moderna en la Universidad de Zaragoza y en la actualidad colaborador extraordinario en la misma, es autor de múltiples e importantes trabajos, entre los que destacan sus aportaciones sobre la historia del regadío en España, la Ilustración y, más recientemente, en torno al surgimiento de un mercado nacional en España en el siglo xvir y el papel que en este proceso desempeñaron tanto el Estado como los grupos mercantiles. Fruto de esta última línea de investigación es la que probablemente sea su obra más célebre hasta la fecha: $L a$ península comercial. Mercado, redes sociales y Estado en España en el siglo XVIII (2012).

Si bien los capítulos incluidos en Bajo el velo del bien público abordan una temática muy variada, en todos ellos se advierte -en mayor o menor grado- el trasfondo de la Ilustración y de los cambios políticos e ideológicos acontecidos en el «largo siglo xvIII), un periodo en el que, tal y como rezaba el programa de las citadas jornadas, se asistió a un recrudecimiento del conflicto entre lo "público» y lo "privado», y a una redefinición del Estado como garante del «bien común».

El libro se inicia con una semblanza personal y académica del homenajeado escrita por E. Fernández Clemente. A esta a le sigue, a modo de introducción, un análisis de R. Fernández sobre la figura de Carlos III, el monarca bajo cuyo reinado se dio precisamente un mayor impulso transformador en aras de dotar a España de un Estado fuerte con capacidad de subordinar los intereses privados a los proyectos reformistas de la monarquía. En dicho capítulo se destacan no solo las motivaciones y logros del programa carolino, sino también los límites -autoimpuestos o no- en los que se movió, los equilibrios que mantuvo y las contradicciones que enfrentó una obra de gobierno que, no olvidemos, no pretendía derribar el Antiguo Régimen, sino reformarlo preservando buena parte de sus elementos.

Después, figuran once capítulos agrupados en dos partes. La primera, dedicada a "Estado y política», comienza con el capítulo de A. Abadía Irache sobre las concordias de censualistas en el Reino de Aragón. En él se aborda el problema del excesivo endeudamiento de los municipios del citado reino una vez finalizada la guerra de sucesión, así como las medidas implementadas para su alivio por parte de las nuevas admi- nistraciones públicas resultantes de los Decretos de Nueva Planta. A continuación, el trabajo de M. Alfonso Mola y C. Martínez Shaw realiza un recorrido exhaustivo por los distintos sistemas que puso en marcha la monarquía española para explotar el comercio con Filipinas desde su conquista en el siglo xvi hasta la desaparición de la Real Compañía de Filipinas en 1834. T. Nava Rodríguez trata la crisis de la monarquía absoluta en el Reino de Nápoles a principios del siglo xIX, centrándose en la figura de Donato Tommasi, teórico del absolutismo ilustrado y alto funcionario al servicio de los Borbones napolitanos. R. Torres Sánchez ofrece una revisión actualizada de la historiografía en torno al fiscal-military sta$t e$, en la que presta especial atención a las implicaciones de este en términos de legitimidad y a la importancia que tuvo no solo la capacidad de los Estados para generar recursos fiscales, sino también la eficacia a la hora de movilizarlos. J. L. Gómez Urdáñez se adentra en lo que él denomina «la cara cruel de la España ilustrada», esto es, los diversos mecanismos represivos empleados durante el Siglo de las Luces contra colectivos e individuos, de los cuales no se libraron ni siquiera los colaboradores más estrechos de la monarquía que habían caído en desgracia. Cierra este bloque el trabajo de B. Yun sobre la corrupción en el imperio español en la Edad Moderna, en el que se defiende la no excepcionalidad del caso analizado -considerado frecuentemente como un ejemplo de corrupción extremo-, y se exponen los motivos que, a juicio del autor, habrían dado lugar a la proliferación de conductas deshonestas en dicha entidad política.

Los capítulos que componen este bloque constituyen, por lo tanto, buenos ejemplos de algunas de las problemáticas que tuvieron que abordar las monarquías absolutas -particularmente la española- en el marco de sus programas de corte ilustrado, a saber: la ejecución de políticas que amenazaban los intereses de grupos específicos como la Iglesia, los gremios locales o la aristocracia terrateniente; la promoción de nuevas élites burocráticas y empresariales más afines a los proyectos de la monarquía; la introducción de cambios significativos que permitieran tanto al Estado como al sector privado un mejor aprovechamiento de los recursos materiales y humanos disponibles, o la persecución de aquellos comportamientos que amenazaran el «bien común» -o al menos a la concepción que de este tenía el Estado-.

La segunda parte, dedicada a ideas y autores, se inicia con el trabajo de M.. D. Albiac, quien desarrolla algunos de los principios morales de la Ilustración mediante el análisis de la obra Noches lúgubres, de José Cadalso. Continúa, J. Astigarraga con un capítulo en el que trata la penetración de la economía política y el constitucionalismo británicos en España en la segunda mitad del siglo xviII a través de la difusión de traducciones de textos anglófilos. N. Guasti analiza la concepción que del «bien público» tenía uno de los grupos que resultaron per- 
judicados por el regalismo ilustrado: los jesuitas, para lo cual se centra en la obra del exjesuita valenciano Javier Andrés. M. ${ }^{a}$ V. López-Cordón estudia la difusión de la tratadística legal y política europea en España durante el siglo xVIII, la divulgación de sus enseñanzas desde las cátedras universitarias y la impronta que este género tuvo en la modernización de cuerpos funcionariales como el diplomático. Finalmente, J. Usoz realiza un repaso sobre las interpretaciones que desde su origen se han hecho sobre el concepto "mercantilismo» -muy distintas entre sí-, así como de los enfoques que han primado en cada una de ellas -entre los que ha habido un claro predominio de las visiones economicistas-.

De este modo, el contenido de estos cinco capítulos contribuye a recalcar la importancia que jugó el sustrato intelectual en la fase final del Antiguo Régimen, tanto en el campo de las políticas públicas como a la hora de promover el afianzamiento nuevos valores. Así mismo, del análisis comparado de estos trabajos se percibe claramente cómo lejos de existir un único modelo para transformar la realidad fueron muchas las ideas que, bajo el paraguas de la Ilustración, aspiraron a tal fin.

A modo de conclusión, Bajo el velo del bien público se trata de un volumen que, desde la heterogeneidad de los trabajos que lo componen, logra presentar un texto bien integrado en torno a las transformaciones políticas e intelectuales del «largo siglo xviII y a los debates que sobre estas cuestiones persisten. Es, pues, una valiosa contribución y una obra que hace honor a la prolífica trayectoria del autor al que homenajea.

José Luis Peña-Mir Investigador independiente

\section{Bibliografía}

Pérez Sarrión, G. (2012). La península comercial. Mercado, redes sociales y Estado en España en el siglo xVIII. Madrid: Marcial Pons.

https://doi.org/10.33231/j.ihe.2022.01.015 